\title{
GOVERNANÇA DOS SISTEMAS JUDICIAIS NO PODER JUDICIÁRIO DE SANTA
} CATARINA

Ramila Rossa ${ }^{1}$

\section{RESUMO}

A informatização dos processos judicias, concluída em janeiro de 2016, no Poder Judiciário Catarinense - PJSC, representou o nascimento de um novo paradigma de trabalho. O artigo estuda a aplicação dos conceitos de Nova Gestão Pública, Governança Pública e Governança de TI à gestão estratégica dos Sistemas Judiciais, diante da sua complexidade e da sua imprescindibilidade à efetivação do Acesso à Justiça. Ao final, apresenta-se a proposta de institucionalizar no PJSC um "Comitê de Governança dos Sistemas Judiciais", porquanto as ferramentas digitais que viabilizam o processo eletrônico tornaram-se indispensáveis à realização do negócio da Justiça.

Palavras-chave: Processo Eletrônico, Nova Gestão Pública, Governança Pública, Governança de TI e Acesso à Justiça.

\section{GOVERNANCE OF JUDICIAL SYSTEMS IN THE JUDICIARY POWER OF SANTA CATARINA}

\begin{abstract}
The article performs a scrutiny on the applications of the new Concepts of Public-Sector Management, Public-Sector Governance, and Information Technology Governance in the scope of an strategic management of Judicial Systems, in light of its complexity and its importance for the effectiveness of the Access of Justice. At the end, there is a proposal of organizing, inside the JPSC, a "Committee of Judicial System Governance", because the digital tools that have set up the electronic process have become mandatory for the performance of Justice.
\end{abstract}

Keywords: Eletronic Process, New Public-Sector Management, Public-Sector Governance, Information Techonology Governance, Access to Justice.

\section{INTRODUÇÃO}

Com a implantação do processo eletrônico no Tribunal de Justiça de Santa Catarina TJSC, em janeiro de 2016, o Poder Judiciário de Santa Catarina - PJSC concluiu a jornada de informatização de seus procedimentos jurisdicionais, inaugurada em 2006, quando o Juizado Especial Cível do Norte da Ilha de Florianópolis, localizado no bairro de Santo Antônio de

\footnotetext{
${ }^{1}$ Pós-graduada em Direito Público pela Universidade do Vale do Itajaí - UNIVALI, cursa Mestrado Profissional em Direito na Universidade Federal de Santa Catarina - UFSC. Graduada em Direito pela UFSC, é servidora do Tribunal de Justiça de Santa Catarina - TJSC desde 2002. Atualmente é Analista de Negócios e Assessora Técnica da Diretoria de Tecnologia da Informação do TJSC, onde atua nas áreas de Governança da TI e gestão dos Sistemas Judiciais da organização. Reside na Avenida Engenheiro Max de Souza, 1588, Bairro Coqueiros, Florianópolis, Santa Catarina, CEP 88080-000. E-mail: ramilarossa@tjsc.jus.br
} 
Lisboa, passou a operar com uma nova versão do Sistema de Automação da Justiça de Primeiro Grau - SAJ/PG, que possibilitou a tramitação totalmente digital dos processos judiciais iniciados naquela unidade jurisdicional.

A forma digital de tramitar os processos judiciais e de praticar os atos processuais representou o nascimento de um novo paradigma de trabalho no PJSC.

A transformação nas rotinas, no modo de receber, analisar e julgar os feitos e no modelo de gestão dos processos de trabalho foi imensa e profunda.

Toda a sociedade e, mais especificamente, as partes que litigam no PJSC, magistrados, servidores e colaboradores da Justiça, ainda estão em fase de adaptação ao novo modelo de oferecimento e efetivação da prestação jurisdicional, pois os processos de trabalho permanecem sob melhoria contínua.

O paradigma atual, de virtualização total dos procedimentos jurisdicionais, pressupõe os Sistemas Judiciais, não mais como meras ferramentas de apoio à atividade fim do PJSC, mas como verdadeiros instrumentos de efetivação do Acesso à Justiça: o sistema e suas funcionalidades agora são o processo. O PJSC deixou de ser uma organização que utiliza a tecnologia digital e passou a ser uma organização digital.

Diante desse novo cenário, o controle, a gestão e o aperfeiçoamento dos Sistemas Judiciais tornaram-se essenciais para concretização da missão e da visão do PJSC, que são, respectivamente: "Realizar Justiça por meio da humanização e da efetividade na prestação adequada da solução de conflitos" e "Ser reconhecido como um Judiciário eficiente, célere e humanizado" (PODER JUDICIÁRIO DE SANTA CATARINA, 2017).

Assim, a construção de práticas de Governança sobre os Sistemas Judiciais, após a transformação ocorrida entre os anos de 2006 e 2016, assumiu um caráter estratégico no âmbito da estrutura administrativa do PJSC.

Diante da imprescindibilidade do exercício de Governança sobre os Sistemas Judiciais, principalmente após a implantação do processo eletrônico no TJSC e, também, em razão da celebração do Contrato n. 239/2015², de Manutenção Evolutiva do SAJ, ocorrida em 18 de dezembro de 2015, instaurou-se, informalmente, no âmbito do Conselho Gestor de Tecnologia da Informação - CGINFO ${ }^{3}$, o "Subcomitê de Priorização de Demandas para o

\footnotetext{
${ }^{2}$ O Contrato n. 239/2015 é o instrumento que rege a relação do PJSC com a Empresa Softplan Planejamento e Sistemas Ltda., e sustenta o processo de manutenção evolutiva do Sistema de Automação da Justiça - SAJ.

${ }^{3}$ Vide Resolução n. 07/2008-GP, do TJSC, Transforma em Conselho Gestor de Tecnologia da - CGINFO a estrutura da Comissão de Gestão de Informatização e dá outras providências. O Conselho Gestor de Tecnologia da Informação foi instituído com o objetivo de buscar incessante a qualidade do serviço público, revisando e
} 
SAJ", com a atribuição de gerir (avaliar e priorizar para desenvolvimento), em nível estratégico, as demandas para o aperfeiçoamento dos Sistemas Judiciais.

Um dos objetivos do presente artigo é demonstrar que o trabalho do Subcomitê, durante os anos de 2016 e 2017, representou significativo avanço à estrutura de Governança do PJSC, na medida em que orientou a Seção de Análise de Negócios - $\mathrm{SAN}^{4}$, da Divisão de Sistemas Judiciais - DSJ, no processo de evolução de todo o ecossistema das aplicações que compõem os Sistemas Judiciais, avaliando e priorizando demandas de aperfeiçoamento, com o fim de tornar o SAJ mais adequado e efetivo à tramitação ideal dos processos judiciais e à entrega da prestação jurisdicional.

A complexidade e o dinamismo do novo modelo de oferecimento da prestação jurisdicional trouxeram, também, a necessidade de que o tema seja abordado a partir da ótica do Pensamento Sistêmico.

Portanto, inicialmente, serão apresentados os conceitos de Nova Gestão Pública, Governança Pública, Governança de Tecnologia da Informação - TI, Pensamento Sistêmico e Acesso à Justiça, aplicáveis ao caso em estudo.

Num segundo momento, será relatada a experiência de atuação do "Subcomitê de Priorização de Demandas para o SAJ" no âmbito da estrutura de Governança de TI do PJSC, nos anos de 2016 e 2017.

O método utilizado para que sejam alcançados os objetivos propostos é o dedutivo, com pesquisa bibliográfica.

O trabalho será concluído com a elaboração de um Projeto de Resolução para a institucionalização de um "Comitê de Governança dos Sistemas Judiciais", a substituir o

atualizando permanentemente os serviços judiciários de $1^{\circ}$ e $2^{\circ}$ Graus, no que se refere ao uso da informática. Compete ao CGINFO: definir as políticas e diretrizes institucionais referentes à aplicação da Tecnologia da Informação no Poder Judiciário do Estado de Santa Catarina; planejar a implantação de recursos computacionais para promover uma gestão de qualidade no Poder Judiciário; acompanhar e controlar a implementação das ações vinculadas ao processo de informatização; e promover a integração com os órgãos do Judiciário estadual e federal, mais especificamente com o Conselho Nacional de Justiça - CNJ, bem como com os demais órgãos do setor público e privado.

${ }^{4}$ São atribuições da Seção de Análise de Negócios de Sistemas Judiciais: receber, propor, analisar e gerir as necessidades de melhorias e novas implementações para os sistemas judiciais do PJSC; subsidiar o CGINFO com informações que permitam a classificação e priorização das evoluções dos sistemas judiciais; manter e disponibilizar, no Portal do Processo Eletrônico, para consulta pública, o catálogo de melhorias e novas implementações avaliadas pelo CGINFO, a fim de garantir a transparência do processo de trabalho; oficializar e gerenciar, junto a empresa desenvolvedora, as demandas de manutenção evolutiva dos sistemas judiciais; desenvolver e aprovar os requisitos dos sistemas judiciais; fornecer subsídios que permitam a fiscalização dos contratos da Divisão de Sistemas Judiciais, relacionados aos trabalhos/procedimentos desenvolvidos pela Seção; atuar como Analistas de Negócios nos projetos da Divisão de Sistemas Judiciais. 
"Subcomitê de Priorização de Demandas para o SAJ", que existe na informalidade, a ser apresentado ao Gabinete da Presidência do PJSC, com o fundamento na imprescindibilidade de construir-se um olhar estratégico e cuidadoso sobre a questão, uma vez que as ferramentas digitais que viabilizam o processo judicial eletrônico tornaram-se instrumentos de efetivação do Acesso à Justiça.

\section{A GESTÃO ESTRATÉGICA DOS SISTEMAS JUDICIAIS NO PJSC E OS CONCEITOS DE NOVA GESTÃO PÚBLICA, GOVERNANÇA PÚBLICA E GOVERNANÇA DE TI}

O presente trabalho propõe, a partir da experiência de atuação do "Subcomitê de Priorização de Demandas para o SAJ" e, diante da mudança de paradigma trazida pela total informatização dos processos judiciais, a institucionalização da uma nova política de Governança dos Sistemas Judiciais para o PJSC, a ser construída com fundamento nos marcos teóricos da Nova Gestão Pública, da Governança Pública e da Governança de TI, sob a ótica do Pensamento Sistêmico e da efetivação do princípio constitucional do Acesso à Justiça.

A Nova Gestão Pública é uma teoria da Administração Pública que surgiu como contraponto ao modelo burocrático weberiano ${ }^{5}$, vigente até o início do século $\mathrm{XX}$, na sociedade ocidental.

Luiz Carlos Bresser Pereira (2000, p. 63-64) relata que a Administração Pública passou por duas grandes reformas ao longo de sua história: a "Reforma Burocrática" que atingiu a Europa e os Estados Unidos no início do século XX e o Brasil nos anos da década de 1930, com o governo Vargas; e a "Reforma Gerencial" ou "Reforma da Nova Gestão Pública". Esta última pode ser dividida em duas "ondas" distintas: a "primeira onda", dos anos 1980, com ênfase no ajuste estrutural das economias em crise (ajuste fiscal, privatização, liberalização do comércio); e a "segunda onda", a partir dos anos 1990, com ênfase nas transformações de caráter institucional.

Christopher Hood (1991, p. 03-19) foi quem primeiro definiu a "Nova Gestão Pública” ou "Administração Pública Gerencial”, a partir da conjunção de sete elementos:

\footnotetext{
${ }^{5} \mathrm{O}$ modelo burocrático weberiano é um modelo organizacional que desfrutou notável disseminação nas administrações públicas durante o século XX em todo o mundo. O modelo burocrático é atribuído a Max Weber, porque o sociólogo alemão analisou e sintetizou suas principais características. O modelo também é conhecido na literatura inglesa como progressive public administration - PPA, referindo-se ao modelo que inspirou as reformas introduzidas nas administrações públicas dos Estados Unidos entre os séculos XIX e XX, durante a chamada progressive era.
} 
profissionalização da gestão nas organizações públicas; padrões de desempenho e medidas de avaliação, com objetivos mensuráveis e claramente definidos; ênfase no controle e nos resultados; desagregação das grandes unidades do setor público; introdução da competição no setor público; uso de práticas de gestão do setor privado; ênfase na disciplina e na utilização dos recursos, cortando custos e procurando maior eficiência e economia.

No caso brasileiro, o Plano Diretor da Reforma do Aparelho do Estado - PDRAE definiu a "Administração Pública Gerencial" como resposta, de um lado, à expansão das funções econômicas e sociais do Estado e, de outro, ao desenvolvimento tecnológico e à globalização da economia mundial, uma vez que ambos deixaram à mostra os problemas associados à adoção do modelo anterior. (MARE, 1995)

Para Leonardo Secchi (2009, p. 347-369), a Nova Gestão Pública (new public management) é, portanto, um modelo normativo pós-burocrático para a estruturação e a gestão da Administração Pública baseado em valores de eficiência, eficácia e competitividade.

Como modelo organizacional que incorpora prescrições para a melhora da efetividade da gestão na Administração Pública, a teoria da Nova Gestão Pública abre caminho para o movimento chamado Governança Pública, que propõe um novo olhar para as organizações públicas segundo a sua função e relação sistêmica com a sociedade.

Ainda, segundo Leonardo Secchi (2009, p. 358):

As teorias do desenvolvimento tratam a Governança como um conjunto adequado de práticas democráticas e de gestão que ajudam os países a melhorar suas condições de desenvolvimento econômico e social. "Boa Governança" é, portanto, a combinação de boas práticas de gestão pública. Governança na linguagem empresarial e contábil significa um conjunto de princípios básicos para aumentar a efetividade de controle por parte de stakeholders e autoridades de mercado sobre organizações privadas de capital aberto.

A adoção de práticas modernas de Governança na Administração Pública se deve à crescente complexidade, dinâmica e diversidade das sociedades, o que coloca os sistemas de governo sob novos desafios, como na hipótese que será estudada.

Dentro do modelo de Governança a Administração Pública desloca seu papel primordial da implementação de políticas administrativas para a coordenação e o controle de suas ações. E esse é exatamente o papel que se proporá para a atuação do "Comitê de Governança dos Sistemas Judiciais” a ser criado no âmbito do PJSC. 
Nesse sentido, a Governança é geradora de instrumentos de colaboração e de construção de um modelo mais transparente e integrador que serve como um impulso ao alcance de interesses da sociedade.

Em termos práticos, o modelo de Governança Pública disponibiliza plataformas organizacionais para facilitar o alcance de objetivos públicos e, no caso presente, para a efetivação do Acesso à Justiça, a partir da gestão do aperfeiçoamento dos Sistemas Judiciais, de forma participativa, com a definição de diretrizes e critérios objetivos para a escolha de demandas a serem priorizadas, levando-se em consideração as reais necessidades da sociedade, que busca seus direitos junto ao PJSC.

No caso em estudo, portanto, pretende-se a aplicação do modelo de Governança Pública à gestão dos Sistemas Judiciais.

Os Sistemas Judiciais são as soluções de Tecnologia da Informação - TI que viabilizam o negócio do PJSC. E qual é o negócio o PJSC? Como negócio entende-se o produto final da atividade judiciária, que é a prestação jurisdicional, a decisão final que resolve o problema dos litigantes.

Assim, mais especificamente, é necessário ampliar o estudo do marco teórico da Governança Pública para a introdução de conceitos próprios da Governança de TI.

O trabalho de José Geraldo Loureiro Rodrigues (2010, p. 27) apresenta os seguintes conceitos de Governança de TI - GTI:

GTI é um modelo operacional de como a organização tomará decisões sobre o uso da Tecnologia da Informação. Aborda decisões sobre a alocação de recursos, a avaliação de iniciativas e riscos de negócios, priorização de projetos, medidas de desempenho e mecanismos de rastreamento, determinação de custos e de como estes são alocados, e a avaliação do valor de investimento de TI.

Ainda, segundo o mesmo autor:

GTI é o alinhamento estratégico da TI com o negócio, de modo que o máximo de valor para o negócio seja alcançado, por meio do desenvolvimento e manutenção de mecanismos de controle e responsabilização da área de TI, bem como da gestão de seu desempenho e de seus riscos.

A norma ISO/IEC 38500 propõe um modelo para a Governança de TI, prevendo que os gestores governem a TI por meio de três atividades principais: avaliação, direção e monitoramento, a saber:

a) Avaliar o uso corrente e futuro da TI; 
b) Dirigir a preparação e implementação de planos e políticas para assegurar que o uso da TI cumpra os objetivos do negócio;

c) Monitorar a conformidade com as políticas e com o desempenho em relação ao que foi planejado.

Na medida em que os Sistemas Judiciais passaram a constituir o próprio instrumento de materialização do Direito, com a implantação do processo eletrônico em todo o PJSC, verificou-se um aumento na complexidade das soluções tecnológicas aplicadas ao negócio da Justiça, que é o oferecimento da prestação jurisdicional. Tal cenário exige uma nova forma de pensar, não fragmentada, menos analítica, mas com foco na visão do todo, uma vez que as questões relacionadas aos Sistemas Judiciais não são mais exclusivamente responsabilidade das áreas da TI.

O padrão de pensamento atual, também chamado de paradigma tradicional da ciência (VASCONCELLOS, 2013), paradigma mecanicista ou, ainda, paradigma cartesiano (ANDRADE, 2014) é reducionista e analítico. O todo é fragmentado e explicado a partir de suas partes simples específicas. As partes, uma vez separadas, são categorizadas e classificadas, o que exige que se esteja sempre decidindo sobre uma coisa ou outra. De acordo com a lógica atual, um objeto não pode pertencer simultaneamente a duas categorias, não ser ele e não ele (princípio da identidade) e um bom sistema de categorias (sistema de classificação) deve se constituir de categorias excludentes entre si, o que se tem chamado de atitude "ou-ou", "ou isto ou aquilo".

A partir desse raciocínio, encontra-se uma única simples causa óbvia para um problema também imaginado como específico. Empiricamente, explicam-se fenômenos em um único relacionamento de causa e efeito e se considera que estes estão próximos no tempo e no espaço, de modo que o amplo contexto se torna irrelevante.

Segundo Aurélio L. Andrade (2014, p. 07-08) "sistema é o conjunto de elementos, concretos ou abstratos, intelectualmente organizados e orientados para um fim" ou "conjuntos logicamente solidários, considerados nas suas relações".

Aristóteles (2002, p. 21) também afirma que "o todo é maior do que a simples soma das suas partes".

Esta é a base para a visão holística subjacente ao Pensamento Sistêmico. A definição do todo expande as fronteiras do sistema de modo que as partes não explicam o todo, mas o todo explica as partes devido às interdependências e inter-relacionamentos entre os sistemas. 
O Pensamento Sistêmico, portanto, é uma forma de raciocinar, um processo cognitivo, que se orienta pelos pressupostos ou características sistêmicas. Em especial, leva a uma capacidade de perceber, modelar e avaliar as consequências das ações de maneira expandida, no tempo e no espaço.

Esta forma de pensar e construir conhecimento é influenciada por uma linguagem de base sistêmica.

Assim, o pensar sistêmico resulta em uma maneira de cogitar e modelar a complexidade do mundo que tem por base processos característicos do paradigma sistêmico, que privilegia o todo, os relacionamentos, a visão de rede, a lógica de causa-e-efeito distantes (circularidade, atrasos), a consideração dos processos dinâmicos, o uso da metáfora do organismo vivo, a estruturação de conhecimento socialmente construído (epistêmico e contextual), a aceitação das descrições aproximadas e das medidas qualitativas, a abordagem intelectual contextualista, uma atitude contemplativa e de perplexidade diante do caos e da incerteza, resultando em ação por auto-organização e que adota processo de aprendizagem transdisciplinar, experiencial, construtivista e generativo (ANDRADE, 2014).

No tocante ao conceito de Acesso à Justiça, o trabalho adota a definição clássica de Mauro Cappelletti e Bryant Garth (1988, p. 8):

A expressão 'acesso à justiça' é reconhecidamente de difícil definição, mas serve para determinar duas finalidades básicas do sistema jurídico - o sistema pelo qual as pessoas podem reivindicar seus direitos e/ou resolver seus litígios sob os auspícios do Estado. Primeiro, o sistema deve ser igualmente acessível a todos; segundo, ele deve produzir resultados que sejam individualmente e socialmente justos.

Nessa linha, Horácio Wanderlei Rodrigues e Eduardo de Avelar Lamy (2016, p. 205) explicam porque o Acesso à Justiça é um metaprincípio constitucional no ordenamento jurídico brasileiro:

É a garantia de acesso à Justiça a garantia maior, sendo apontada por muitos como o principal entre os direitos humanos, sem o qual nenhum outro poderia ser legitimamente garantido dentro do Estado Democrático de Direito. A manifestação do Poder Judiciário, no exercício legítimo da função jurisdicional, é a manifestação do próprio Estado na busca da concretização de seus objetivos, em especial a tutela dos direitos fundamentais.

Diante das visões acima expostas conclui-se que a garantia de Acesso à Justiça não significa apenas a garantia de acesso e apreciação das demandas pelo Poder Judiciário. Sua extensão é bem mais ampla e busca garantir os meios adequados de acesso, a celeridade dos procedimentos, a devida resposta ao problema trazido ao juízo, a efetividade do resultado, 
mediante instrumentos eficientes de execução, e segurança jurídica para as partes, tornando definitivo o resultado final.

Para Ada Pelegrini Grinover (1975, p. 08-09) o Acesso à Justiça é considerado um metaprincípio constitucional, portanto, pois concentra um conjunto de direitos e garantias constitucionais, chamados de princípios constitucionais do processo.

Os princípios constitucionais do processo são mandamentos que visam estabelecer direitos e garantias fundamentais de todos os cidadãos. Os direitos fundamentais que interessam ao presente estudo são: garantia da celeridade e a duração razoável do processo, o direito à prestação jurisdicional objetiva e efetiva, o devido processo legal e constitucional, o direito à publicidade dos atos processuais, o contraditório e a ampla defesa e a fundamentação das decisões judiciais.

Contudo, nos últimos anos a Justiça Brasileira tem enfrentado uma crise sem precedentes, principalmente em razão da demora no oferecimento da prestação jurisdicional.

Ada Pellegrini Grinover (1998, p. 20-21), em seu livro “O Processo em Evolução”, faz referência à crise da justiça pela qual o Poder Judiciário vem passando ante a carência da desformalização processual em busca de um processo mais rápido, simples e econômico. Contudo, ela considera que essa tribulação não tem apenas aspectos negativos:

A crise, prospectivamente, leva - ao menos deveria levar - à renovação, segundo esquemas adequados à realidade emergente. [...] há que extremar, na crise que se generaliza como sendo própria do Judiciário, seus diversos aspectos, ora atinentes à crise estrutural de um dos Poderes; ora peculiares à mentalidade dos operadores da justiça; ora próprios da inadequação dos controles sobre o exercício da função jurisdicional.

Barbosa Moreira (1983, p. 105) classicamente aponta que a excessiva demora na duração do processo deve-se a causas complexas e variadas e elenca como principais as seguintes: falha na organização judiciária, deficiência na formação profissional dos operadores do Direito, precariedade das condições de desenvolvimento da atividade judicial e o uso arraigado de métodos de trabalho obsoletos e irracionais.

E é nesse contexto, de inefetividade do processo e de desconcretização do metaprincípio constitucional do Acesso à Justiça, que surge o processo eletrônico, como uma resposta moderna e tecnológica à crise da Justiça.

Nos dizeres de Sérgio Renato Tejada (2006):

[...] além de combater a morosidade processual, o processo virtual ainda melhora o Acesso à Justiça e a transparência do Poder Judiciário. Isso porque, o processo eletrônico pode ser manejado em horário integral, isto é, 
as portas da Justiça estão sempre abertas para o jurisdicionado. Assim, embora ainda seja necessário o aperfeiçoamento de muitos aspectos que afetam diretamente o desenrolar do processo, como a qualificação da mão de obra e a uniformização dos procedimentos adotados pelos Tribunais, cuja autonomia para se auto-gerenciar acaba diferenciando-os no que diz respeito à utilização da tecnologia digital, dificultando a atuação dos operadores do Direito, o processo totalmente eletrônico trará a consolidação de um anseio própria da sociedade da informação tecnológica.

Assim, a informatização total do PJSC possibilitará a colheita e a sistematização de informações, a serem extraídas diretamente da base de dados dos Sistemas Judiciais e o conjunto dessas informações contribuirá para o aperfeiçoamento dos processos de trabalho e para a identificação das oportunidades de melhoria na gestão do negócio judiciário, com vistas à implantação de técnicas próprias de Governança Pública, com a finalidade de tornar efetiva a prestação jurisdicional.

Para Aires José Rover (2015):

Neste contexto, o governo eletrônico passa a ser um momento especial na evolução do estado e da sociedade. Ele representa para a chamada revolução da informação um avanço inesperado e a razão disso é a relativização do tempo e do espaço. A atuação hoje é global e mesmo que o governo atue num espaço local ou tópico necessita ter um padrão global de administração. A interação entre as novas tecnologias, a sociedade e o Poder Público emoldura um momento único do qual emergem, simultaneamente, desafios enormes e vantagens sociais incríveis. Neste contexto, o aparecimento do Governo Eletrônico é uma decorrência das velhas e novas demandas da sociedade.

Por fim, é preciso anotar que, como efeito direto da informatização do processo judicial, haverá o deslocamento da força de trabalho de todo o aparato do Poder Judiciário para a atividade-fim, para o negócio da Justiça, para aquilo que é essencial, para o tratamento da dor há tanto exposta em razão da resposta tardia e da ineficiência, características atribuídas à forma não-gerencial e não-tecnológica de se enfrentar o problema da Justiça.

\section{A EXPERIÊNCIA DE TRABALHO COM O "SUBCOMITÊ DE PRIORIZAÇÃO DE DEMANDAS PARA O SAJ": DA ATUAÇÃO INFORMAL À EFETIVAÇÃO DO ACESSO À JUSTIÇA, NO ÂMBITO DO TJSC.}

Embora a virtualização dos processos judiciais no PJSC tenha se iniciado em 2006, com a implantação de uma nova versão do SAJ/PG, sistema desenvolvido pela Empresa Softplan Planejamento e Sistemas Ltda., até a celebração do Contrato n. 239/2015, de 
Manutenção Evolutiva do SAJ, não havia, no âmbito da estrutura administrativa do PJSC, um órgão responsável diretamente pelo processo de gestão (avaliação e priorização para desenvolvimento) das demandas para a evolução e o aperfeiçoamento dos Sistemas Judiciais.

O processo judicial eletrônico modificou sobremaneira as rotinas de trabalho nos cartórios judiciais do PJSC, uma vez que muitos procedimentos foram automatizados, como, por exemplo, a distribuição de processos, a juntada de petições intermediárias e a comunicação dos atos processuais.

Para viabilização dos novos procedimentos, verificou-se a necessidade de desenvolvimento e implantação de novas funcionalidades nos Sistemas Judiciais, ou de aperfeiçoamento das ferramentas já existentes e, em alguns casos, alteração de suas regras de funcionamento.

A sustentação dos Sistemas Judiciais, bem como a gestão das alterações e das novas implementações necessárias ao atendimento da demanda dos cartórios judiciais, gabinetes de magistrados e demais setores do PJSC, atualmente, é feita pela Divisão de Sistemas Judiciais - DSJ, da Diretoria de Tecnologia da Informação - DTI, vinculada à Diretoria-Geral Administrativa - DGA do PJSC.

Ocorre que, durante o período compreendido entre abril de 2013 a dezembro de 2015, o PJSC permaneceu sem cobertura contratual para solicitar, à Empresa Softplan Planejamento e Sistemas Ltda., a implementação de novas funcionalidades nos Sistemas Judiciais, razão pela qual todas as demandas a serem desenvolvidas foram sobrestadas.

Portanto, quando da celebração do Contrato n. 239/2015, de Manutenção Evolutiva do SAJ, que normatizou o processo de evolução dos Sistemas Judiciais, existia, na DSJ, uma lista com inúmeras demandas de alteração e/ou novas implementações a serem desenvolvidas para os Sistemas Judiciais, chamada de backlog de novas implementações do SAJ ou catálogo de melhorias.

O Contrato n. 239/2015, instituiu uma série de obrigações ao PJSC e também à empresa contratada e que mantém os Sistemas Judiciais da Justiça Catarinense, dentre elas, estabeleceu que serão desenvolvidas e entregues 4 (quatro) novas versões dos Sistemas Judiciais por ano, 1 (uma) nova versão a cada 3 (três) meses, conforme o disposto no Anexo IV - Versões Ordinárias do Sistema, do contrato. Cada nova versão, que corresponde a 1 (um) ciclo de desenvolvimento, conterá um conjunto de funcionalidades a serem demandadas pelo 
PJSC, de acordo com o previsto na cláusula 5, também do referido contrato (PODER JUDICIÁRIO SANTA CATARINA, 2018).

Assim, a cada novo ciclo de desenvolvimento seria necessário escolher, dentre as inúmeras demandas existentes no backlog de novas implementações do SAJ, quais comporiam o ciclo evolutivo.

À luz dos conceitos trazidos na primeira parte do artigo, torna-se evidente que a gestão da evolução e do aperfeiçoamento dos Sistemas Judiciais adquiriu um caráter estratégico para o PJSC, após a virtualização dos processos judiciais, uma vez que agora o sistema e suas funcionalidades são o processo e, portanto, viabilizam o negócio da Justiça.

Diante desse novo cenário, os gestores e técnicos da DSJ/DTI propuseram, no início do ano de 2016, para que fosse possível dar cumprimento às obrigações do Contrato 239/2015, a criação de um "Subcomitê de Priorização de Demandas para o SAJ", instituído no âmbito do Conselho Gestor de Tecnologia da Informação - CGINFO, órgão que era responsável, na época, até a edição da Resolução GP n. 5, de 2 de fevereiro de $2018^{6}$, por fazer a gestão, em nível estratégico, do uso da tecnologia da informação aplicada aos serviços judiciários no PJSC.

Ao "Subcomitê de Priorização de Demandas para o SAJ" foi atribuída a função de deliberar sobre as demandas de desenvolvimento para a evolução dos Sistemas Judiciais e sua composição contava com 4 (membros): 1 (um) Juiz Substituto de Segundo Grau, Coordenador do CGINFO, 1 (um) Juiz de Direito Assessor da Presidência do PJSC, 1 (um) Juiz Corregedor no Núcleo II de Estudos, Planejamento e Projetos da Corregedoria-Geral da Justiça - CGJ e 1 (um) Juiz de Direito representante da Associação dos Magistrados Catarinenses - AMC.

No âmbito da DSJ/DTI a Seção de Análise de Negócios - SAN mapeou, tendo como base as regras dispostas no Contrato 239/2015, o processo de trabalho de gestão, análise e especificação de demandas de evolução para o SAJ e, portanto, ficou encarregada de conduzir

\footnotetext{
${ }^{6}$ Importante esclarecer que o CGINFO foi extinto pelo art. 16, inciso III, da Resolução GP n. 5, de 2 de fevereiro de 2018, que reestruturou a Presidência do Tribunal de Justiça de Santa Catarina e estabeleceu um novo organograma, com alteração da vinculação administrativa dos setores e órgãos citados na resolução. A mesma resolução, contudo, instituiu Comitê de Governança de Tecnologia da Informação e Comunicação, e atribuiu ao Presidente do Tribunal de Justiça e aos seus Juízes Auxiliares as seguintes funções: I - planejar a implantação de recursos computacionais para promover uma gestão de qualidade no Poder Judiciário; II - acompanhar e controlar as ações vinculadas ao processo de informatização; e III - promover a integração de sistemas informatizados com órgãos do Judiciário e dos setores público e privado.
} 
os trabalhos de priorização de novas implementações para comporem os ciclos evolutivos dos Sistemas Judiciais, junto ao Subcomitê.

Ao compilar todas as demandas de alteração dos Sistemas Judiciais no backlog de novas implementações, a equipe da SAN catalogou 133 (cento e trinta e três) pedidos para os sistemas de primeiro grau (SAJ/PG) e 130 (cento e trinta) para os sistemas de segundo grau (SAJ/SG). Os pedidos chegam à SAN oriundos dos mais diversos setores do PJSC, como sugestões de servidores, magistrados, colaboradores da justiça, demandas institucionais das Diretorias e CGJ, por exemplo.

Como método de avaliação das demandas foi proposta a seguinte classificação, aos membros do Subcomitê:

1. Essencial: são requisitos imprescindíveis, que devem ser necessariamente implementados. É fundamental para o sistema, não sendo possível aplicar soluções de contorno ou paliativos para eles;

2. Importante: representa um item de alta prioridade que deverá ser incluído no sistema. Trata-se de um requisito crítico, mas que pode ser atendido temporariamente por soluções de contorno ou paliativos;

3. Desejável: descreve um requisito que é considerado desejável, mas não necessário, pois não compromete as funcionalidades básicas do sistema, e que poderá ser desenvolvido no futuro. Sem um requisito desejável o sistema deve funcionar de maneira satisfatória, atendendo completamente seu objetivo;

4. Opcional: representa um item que não é indispensável e que por isso não deve ser priorizado para desenvolvimento a curto ou médio prazo, mas que pode ser considerado no futuro.

Além disso, os membros poderiam indeferir os pedidos, excluindo-os do catálogo de melhorias dos Sistemas Judiciais.

Ao final da análise e da classificação, para os sistemas de primeiro grau foram identificadas 45 (quarenta e cinco) demandas essenciais, 38 (trinta e oito) importantes, 25 (vinte e cinco) desejáveis, 11 (onze) opcionais e 14 (quatorze) indeferidas. Para os sistemas de segundo grau foram apontadas 17 (dezessete) demandas essenciais, 22 (vinte e duas) importantes, 16 (dezesseis) desejáveis, 15 (quinze) opcionais e 60 (sessenta) pedidos indeferidos.

Após a classificação, surgiu, então, a necessidade de se definir uma ordem de prioridade para o desenvolvimento das demandas, porquanto os ciclos evolutivos possuem uma cota/quantidade de alterações que podem ser solicitadas à empresa desenvolvedora, prevista contratualmente. 
Para o enfileiramento, cabe apenas mencionar, foi aplicada a matriz GUT, sigla para "Gravidade, Urgência e Tendência"7, ferramenta utilizada na priorização de estratégias, tomadas de decisão e solução de problemas de organizações e/ou projetos.

Com a classificação e o enfileiramento dos pedidos foi possível definir, estrategicamente e a partir de uma visão dos gestores, ligada diretamente ao negócio do PJSC, quais seriam as demandas com maior prioridade e que, se desenvolvidas e implementadas, potencializariam as atividades nas unidades judiciárias do PJSC, com o aumento da produtividade, a melhora nas condições de trabalho dos servidores e magistrados e a ampliação/aperfeiçoamento dos instrumentos de Acesso à Justiça aos jurisdicionados e aos profissionais do Direito.

O trabalho de classificação e enfileiramento das demandas vem sendo realizado, desde a sua proposição e, como resultado, foi disponibilizado aos usuários internos e externos, por meio do Portal do Processo Eletrônico, na forma do catálogo de melhorias do SAJ, que pode ser consultado na página do PJSC, no seguinte endereço eletrônico: <https://www.tjsc.jus.br/web/processo-eletronico/catalogo-de-melhorias-do-saj>.

Como resultado do trabalho realizado pelo "Subcomitê de Priorização de Demandas para o SAJ", além da construção e divulgação democrática do catálogo de melhorias dos Sistemas Judiciais do PJSC, ao longo dos anos de 2016 e 2017 foram desenvolvidas e implementadas, por exemplo, as seguintes funcionalidades: intimação eletrônica para sociedade de advogados, integração dos Sistemas Judiciais do PJSC com o Sistema Integrado de Segurança Pública do Estado de Santa Catarina - SISP, Integração dos Sistemas Judiciais com o Sistema de Depósitos Judiciais do PJSC - SIDEJUD, novo módulo de plantão judicial

\footnotetext{
${ }^{7}$ Gravidade: a gravidade, representada pela letra G, diz respeito ao impacto que o problema analisado irá gerar nas pessoas, nos processos e/ou resultados da organização.Os danos possíveis de serem gerados podem ser avaliados quantitativamente ou qualitativamente, com seus efeitos sendo analisados de médio ou a longo prazo.Por exemplo, um determinado problema pode gerar a falência do negócio (consequência detectada por meio da análise de número). A gravidade pode ser avaliada em uma escala de 1 a 5 , sendo: sem gravidade (1), pouco grave (2), grave (3), muito grave (4), altamente grave (5).

Urgência: a urgência, representada pela letra $\mathrm{U}$, é o tempo disponível para a resolução de um determinado problema. Quanto maior for a urgência de um problema, menor será o tempo para resolvê-lo. Mas podem ser considerados problemas de grande urgência aqueles com prazos definidos por lei ou que envolvam tempo de resposta para clientes.Assim como ocorre na gravidade, a urgência de um problema também pode ser avaliada pela escala: pode esperar (1), pouco urgente (2), urgente (3), muito urgente (4) e necessita atitude imediata (5). Tendência: a tendência, simbolizada pela letra T, é analisada pelo padrão ou previsão de evolução do problema com o passar do tempo.Nesse caso, pode-se avaliar a tendência de um problema a se tornar ainda maior considerando as possíveis consequências que ele terá na ausência de ações para solucioná-lo. A escala a ser usada na avaliação da tendência é: não irá mudar (1), irá piorar a longo prazo (2), irá piorar a médio prazo (3), irá piorar a curto (4), piora imediata (5).
} 
para o segundo grau, controle biométrico de apresentação à Justiça, integração entre os Sistemas do PJSC e do Tribunal Regional Federal da $4^{\mathrm{a}}$ Região - TRF4, disponibilização do módulo para cálculo de custas automatizado via web, integração dos Sistemas Judiciais do PJSC com o Banco Nacional de Monitoramento de Prisões do Conselho Nacional de Justiça $\mathrm{BNMP} / \mathrm{CNJ}$.

\section{CONCLUSÃO}

O novo paradigma trazido pela virtualização dos processos judiciais tornou os Sistemas Judiciais extremamente complexos e os fez imprescindíveis à realização do negócio do PJSC, que passou a ser uma organização digital.

Tal fato torna evidente a necessidade de se promover uma gestão estratégica no processo de evolução de todo o ecossistema das aplicações que compõem os Sistemas Judiciais, avaliando e priorizando demandas de aperfeiçoamento, com o fim de tornar o SAJ, ou qualquer outro sistema a ser adotado pelo PJSC, mais adequado e efetivo à tramitação ideal dos processos judiciais e à entrega da prestação jurisdicional.

Segundo os conceitos de Nova Gestão Pública, Governança Pública e Governança de TI, aplicáveis ao caso em estudo, a gestão eficiente dos Sistemas Judiciais passa pela atuação dos gestores: a) em nível estratégico (Direção do PJSC, Desembargadores e Magistrados), b) em nível tático (Diretores da área Administrativa, Judiciária e de TI) e c) em nível operacional (servidores analistas e técnicos administrativos, judiciários e de sistemas).

Nos anos de 2016 e 2017 o envolvimento dos gestores foi organizado no âmbito do "Subcomitê de Priorização de Demandas para o SAJ", cujo trabalho foi descrito no segundo tópico do presente artigo, porém o Subcomitê atuou na informalidade, ou seja, não faz parte da estrutura administrativa do PJSC, e em resposta à necessidade de cumprimento das obrigações previstas no Contrato 239/2015, de Manutenção Evolutiva do SAJ.

Portanto, conclui-se que há a necessidade de institucionalização de um "Comitê de Governança dos Sistemas Judiciais" no âmbito da estrutura de Governança do PJSC, por meio de resolução a ser editada pela Gabinete da Presidência. Para tanto, apresenta-se a seguir, uma minuta de proposta de resolução, baseada na experiência de trabalho com o "Subcomitê de Priorização de Demandas para o SAJ":

RESOLUÇÃO GP N. X 
Cria o Comitê de Governança dos Sistemas Judiciais e disciplina o seu funcionamento.

O PRESIDENTE DO TRIBUNAL DE JUSTIÇA DE SANTA CATARINA, no uso de suas atribuições e considerando o disposto na Resolução n. 211, de 15 de dezembro de 2015, do Conselho Nacional de Justiça, que instituiu a estratégia nacional de tecnologia da informação e comunicação do Poder Judiciário (ENTIC-JUD), relativo à satisfação dos usuários e à obrigatoriedade da constituição e manutenção de estrutura organizacional compatível com o macroprocesso de governança e gestão, especificamente quanto à evolução dos sistemas judiciais;

Considerando as necessidades institucionais relacionadas aos Sistemas Judiciais e ao cumprimento da missão e da visão do Poder Judiciário de Santa Catarina;

RESOLVE:

Art. $1^{\circ}$ Fica instituído o Comitê de Governança dos Sistemas Judiciais, órgão auxiliar vinculado diretamente à Presidência do Tribunal de Justiça, de caráter permanente, com a finalidade de deliberar sobre as demandas de desenvolvimento para a evolução dos sistemas judiciais do Poder Judiciário de Santa Catarina.

Art. $2^{\circ}$ Compete ao Comitê de Governança dos Sistemas Judiciais:

I - atuar, em nível estratégico, junto à Divisão de Sistemas Judiciais da Diretoria de Tecnologia da Informação, no planejamento e no controle da evolução dos sistemas judiciais;

II - estabelecer critérios a serem aplicados na seleção e priorização das demandas destinadas à evolução dos sistemas judiciais;

III - apreciar as demandas destinadas à evolução dos sistemas judiciais, decidindo pela sua seleção ou recusa.

IV - classificar e priorizar das demandas selecionadas.

Art. $3^{\circ} \mathrm{O}$ Comitê de Governança dos Sistemas Judiciais será composto por 3 magistrados, a serem indicados pela Presidência do Tribunal de Justiça de Santa Catarina.

$\S 1^{\circ}$ A formação do Comitê de Governança dos Sistemas Judiciais será estabelecida a cada nova gestão do Tribunal de Justiça de Santa Catarina.

$\S 2^{\circ} \mathrm{O}$ mandato dos integrantes indicados no caput encerrar-se-á juntamente com o término do mandato da Presidência do Tribunal de Justiça de Santa Catarina, admitindo-se a recondução.

Art. $4^{\circ} \mathrm{O}$ Comitê de Governança dos Sistemas Judiciais reunir-se-á ordinariamente 4 (quatro) vezes ao ano e, extraordinariamente, a seu critério, sempre que for solicitado pela Divisão de Sistemas Judiciais da Diretoria de Tecnologia da Informação.

Parágrafo Único. As deliberações do Comitê de Governança dos Sistemas Judiciais poderão ocorrer com a maioria de seus membros presentes.

Art. $5^{\circ}$ Os casos omissos serão resolvidos no âmbito da Presidência do Tribunal de Justiça de Santa Catarina.

Art. $6^{\circ}$ Revogam-se as disposições contrárias.

Art. $7^{\circ}$ Esta resolução entra em vigor na data de sua publicação.

PRESIDENTE DO TRIBUNAL DE JUSTIÇA DE SANTA CATARINA

Por fim, importante ressaltar que, um dos riscos inerentes à não institucionalização de um "Comitê de Governança dos Sistemas Judiciais" seria a inviabilização do trabalho e da 
gestão das demandas relacionadas ao aperfeiçoamento dos Sistemas Judiciais, com a consequente responsabilização do PJSC pelos prejuízos causados à sociedade, em razão da precariedade e até da inexistência do oferecimento da prestação jurisdicional.

\section{REFERÊNCIAS}

ARAÚJO, Marcos da Silva. A dinâmica da exclusão digital na era da informação.

Disponível em: http://www.webartigos.com/artigos/a-dinamica-da-exclusao-digital-na-era-dainformacao/88/. Acesso em: 23 set. 2016.

ANDRADE, Aurélio L. O Curso de Pensamento Sistêmico. $1^{\text {a }}$ ed. São Paulo: Digital Publish \& Print Editora, 2014.

ARISTÓTELES. Metafísica. São Paulo: Edições Loyola, 2002.

BAGGENSTOSS, Grazielly Alessandra. Teoria dos Sistemas Humanizada: a modelagem garantista das funções jurisdicional e legislativa. Rio de Janeiro: Lumen Juris, 2015.

BRASIL. MARE. Plano Diretor da Reforma do Aparelho do Estado. Brasília: MARE, 1995.

BRESSER PEREIRA, Luiz Carlos. A reforma gerencial da administração pública brasileira. In: Moderna Gestão Pública: dos meios aos resultados. Oeiras: INA, 2000, p. 55-72.

Bresser-Pereira, Luiz Carlos. Da administração burocrática à gerencial. Revista do Serviço Público, v. 47, n. 1, 1996.

CAPPELLETTI, Mauro. GARTH Bryant. Acesso à Justiça. Tradução Ellen Gracie Northfleet. Porto Alegre: Sergio Antônio Fabris Editor, 1988.

CASTELLS, Manuel. A era da Informação: economia, sociedade e cultura. Vol. II. Traduzido por Klauss Brandini Gerhardt. São Paulo: Paz e Terra, 2010.

CASTELLS, Manuel. A Galáxia da Internet. Reflexões sobre a Internet, os negócios e a sociedade. Tradução de Mara Luiza X. de A. Borges. Rio de Janeiro: Zahar, 2003

CASTELLS, Manuel. A sociedade em Rede. Vol. I. Oitava Edição. Traduzido por Roneide Venancio Majer São Paulo: Paz e Terra, 1999.

CONSELHO GESTOR DE TECNOLOGIA DA INFORMAÇÃO - CGINFO. Disponível em: $\langle$ https://www.tjsc.jus.br/conselho-gestor-de-tecnologia-da-informacao >. Acesso em: 24 nov. 2017.

COSTA, Cristiane Barbosa da. O processo eletrônico como forma de efetivação do direito ao acesso à Justiça e do princípio da razoável duração do processo. Revista da Esmat 13 - 
Escola Superior da Magistratura Trabalhista da Paraíba: Amatra 13. João Pessoa - Paraíba, v.2, n.2, nov. 2009.

GARCIA, Sérgio Renato Tejada. Processo virtual: uma solução revolucionária para a morosidade. Conselho Nacional de Justiça, Brasília, DF, 09 jun. 2006. Disponível em: http://www.cnj.jus.br/atos-administrativos/atos-da-presidencia/433-informacoespara/imprensa/artigos/13304-processo-virtual-uma-solu-revoluciona-para-a-morosidade. Acesso em: 23 set. 2016.

GRINOVER, Ada Pelegrini. Os Princípios Constitucionais e o Código de Processo Civil. São Paulo: Bushatasky, 1975.

GRINOVER, Ada Pelegrini. O processo em evolução. Rio de Janeiro: Forense Universitária, 1998, p. 20-21.

HAINES, Stephen G. Guia de Bolso do Gerente: Pensamento Sistêmico e Aprendizagem. Rio de Janeiro: Qualitymark, 2002.

HOOD, Christopher. Public management for all seasons? In: Public Administration, Londres, v.69, nº 01, 1991, p. 03-19. Disponível em:

$<$ http://www.christopherhood.net/pdfs/npm encyclopedia entry.pdf $>$. Acesso em: 23 nov. 2017.

INTERNATIONAL ORGANIZATION FOR STANDARDIZATION - ISO, INTERNATIONAL ELECTROTECHNICAL COMMISSION - IEC. International Standard ISO/IEC 38500 - Corporate governance of information technology. 2008. Disponível em: https://www.iso.org/standard/62816.html. Acesso em: 24 nov. 2017.

LEITE, Martha Franco; REBOUÇAS, Gabriela Maia. Desafios de um judiciário brasileiro em números: a modernização a serviço de que $(\mathrm{m})$ ?. In: BARBOSA, Claudia Maria;

CARVALHO NETO, Frederico da Costa; LEAL, Rogério Gesta (Org.). Política judiciária e administração da justiça. Florianópolis: Conpedi, 2015. p. 64-81. Disponível em: <http://www.conpedi.org.br/publicacoes/c178h0tg/7z8sksbh/9wFg61Qyr8ddOx9s.pdf>. Acesso em: 23 set. 2016.

LIMA, Tatiana Cristina; CRUZ, Marcus Vinicius Gonçalves da. O Conselho Nacional de Justiça e as Reformas do Poder Judiciário: aspectos da Tecnologia da Informação. In: XXXV ENCONTRO DA ANPAD, 25., 2011, Rio de Janeiro. Anais do XXXV EnANPAD. Rio de Janeiro: Anpad, 2011. p. 1 - 17. Disponível em:

<http://www.anpad.org.br/admin/pdf/APB3066.pdf>. Acesso em: 23 set. 2016.

MIGLIAVACCA, Luciano de Araujo. A Virtualização do Processo como meio de concretização do Direito Fundamental à razoável duração do processo na Sociedade da Informação. In: ADOLFO, Luiz Gonzaga Silva (Org.). Direitos Fundamentais na Sociedade de Informação. Florianópolis: UFSC/GEDAI, 2012.

MEZZAROBA, Orides. ROVER, Aires José. Democracia Digital e Governo Eletrônico. Florianópolis: Conceito Editorial, 2012. 
MEZZAROBA, Orides; MONTEIRO, Cláudia Servilha. Manual de metodologia da pesquisa no Direito. 4. ed. São Paulo: Saraiva, 2010.

MOREIRA, Barbosa. Notas sobre o problema da efetividade do processo. Revista da Ajuris, Porto Alegre: n. 29, nov., 1983, p. 105.

PODER JUDICIÁRIO DE SANTA CATARINA. Missão e Visão. Disponível em: <https://www.tjsc.jus.br/missao-e-visao >. Acesso em: 21 nov. 2017.

PODER JUDICIÁRIO DE SANTA CATARINA. Contratos e Convênios. Disponível em: <https://www.tjsc.jus.br/contratos-e-convenios >. Acesso em: 08 abr. 2018.

RODRIGUES, José Geraldo Loureiro. Diretrizes para implantação da governança de TI no setor público brasileiro à luz da teoria institucional. 2010. $170 \mathrm{f}$. Dissertação (Mestrado em Informática) - Universidade Católica de Brasília, Brasília, 2010.

RODRIGUES, Horácio Wanderlei. LAMY, Eduardo de Avelar. Teoria Geral do Processo. 4. ed. rev., atual. e ampl. São Paulo: Atlas, 2016.

ROVER, Aires José. (org.). Direito e Informática. SP: Manole, 2004.

ROVER, Aires José. Informática no direito: inteligência artificial, introdução aos sistemas especialistas legais. Curitiba: Juruá, 2001.

ROVER, Aires José (Org.). Direito, Sociedade e Informática: limites e perspectivas da vida digital. Florianópolis: Fundação Boiteux, 2000.

ROVER, Aires José. A tecnologia como fator de democratização do direito. Sequiência Estudos Jurídicos e Políticos, Florianópolis, 19(25): 50-55, dez./1997.

ROVER, Aires José. Introdução ao Governo Eletrônico. Revista Democracia Digital e Governo Eletrônico. 17 jun. 2015. Disponível em:

http://buscalegis.ufsc.br/revistas/index.php/observatoriodoegov/article/view/30883/30643.

Acesso em: 23 set. 2016.

RUSCHEL, A.J; ROVER, Aires José; SCHNEIDER, J. Governo Eletrônico: O Judiciário na Era do Acesso. In Pilar Lasala Calleja (ed.) La Administración Electrónica como Herramienta de Inclusión Digital, LEFIS Series 13, Zaragoza: Prensas Universitaria de Zaragoza, 2011. Disponível em: http://egov.ufsc.br/portal/conteudo/artigo-governoeletr\%C3\%B4nico-o-judici\%C3\%A1rio-na-era-do-acesso. Acesso em: 23 set. 2016.

RUSCHEL, A.J; ROVER, Aires José; SCHNEIDER, J. Business Intelligence: Governo Eletrônico na Administração da Justiça. Dispoível em:

http://www.egov.ufsc.br/portal/sites/default/files/business_inteligente.pdf. Acesso em: 23 set. 2016. 
SECCHI, Leonardo. Modelos organizacionais e reformas da administração pública. Rev. Adm. Pública. Rio de Janeiro, v. 43, n. 2.

SENGE, Peter. A Quinta Disciplina: arte e prática da organização que aprende. $28^{a}$ ed. Rio de Janeiro: BestSeller, 2012.

SILVA, Helena de Souza. Fragilidades na Gestão de TI: O Pensamento Sistêmico como solução. Beau Bassin: Novas Edições Acadêmicas, 2017.

VASCONCELlOS, Maria José Esteves de. Pensamento Sistêmico - O Novo Paradigma da Ciência. 10a ed. Campinas: Papirus, 2013. 